\title{
Atlantic cod Gadus morhua in the Mediterranean: a surprising immigrant
}

\author{
G. Morey ${ }^{1, *}$, B. Morales-Nin ${ }^{2}$, F. Riera ${ }^{1}$, A. Grau ${ }^{1}$, A. J. Geffen ${ }^{3}$, S. Pérez-Mayol ${ }^{2}$, \\ M.-Y. Chang ${ }^{3}$, A. M. Grau ${ }^{1}$

\begin{abstract}
${ }^{1}$ Direcció General de Medi Rural i Marí, Govern de les Illes Balears, Foners 10, Palma 07006, Spain
\end{abstract} \\ ${ }^{2}$ Institut Mediterrani d'Estudis Avançats IMEDEA (CSIC/UIB), Miquel Marquès 21, Esporles 07190, Spain \\ ${ }^{3}$ Department of Biology, University of Bergen, PO Box 7803, 5020 Bergen, Norway
}

\begin{abstract}
A female cod Gadus morhua L. $87.1 \mathrm{~cm}$ total length was captured off Mallorca (Balearic Islands, NW Mediterranean) in June 2009 by a bottom trawler between 63 and $110 \mathrm{~m}$ depth. This is the first documented occurrence of the species in the Mediterranean. The fish was mature, with a very low hepatosomatic index and atretric gonads. Age assigned from the otoliths was 4 yr. The otolith chemical composition indicated that this fish entered the Mediterranean late in its first year of life.
\end{abstract}

KEY WORDS: Gadus morhua $\cdot$ Migration $\cdot$ Mediterranean $\cdot$ Otolith analysis Resale or republication not permitted without written consent of the publisher

\section{INTRODUCTION}

Atlantic cod Gadus morhua L. is widely distributed throughout the continental shelves in the North Atlantic. Along the European coasts, it reaches the Bay of Biscay (ca. $47^{\circ} \mathrm{N}$; Cohen et al. 1990), with little evidence of its presence further south (Bañon et al. 2010). Cod is capable of undertaking long distance migrations (ca. 1000 km; Jørgensen et al. 2008), and its migratory behavior and range may change over its life cycle.

The Mediterranean is a semi-enclosed sea with a natural entrance in the west, the Straits of Gibraltar. The inflow of Atlantic waters through the Straits of Gibraltar has marked the character of the Mediterranean marine biota for the last 5.3 million years, although in recent years, an increase in the immigration rate from the tropical Atlantic has been observed (Massutí et al. 2010).

Here, we report the first record of cod in the Mediterranean, which also represents the first occurrence of a species of boreal Atlantic origin off the Balearic Islands in the last $40 \mathrm{yr}$. We explored the life history of this fish and its possible migratory behavior using the information encoded in its otoliths.

\section{MATERIALS AND METHODS}

\section{Fish characteristics}

On 24 June 2009, 1 cod Gadus morhua was captured by a commercial bottom trawler at $\sim 9$ nautical miles off the south coast of Mallorca Island $\left(39^{\circ} 15^{\prime} 37^{\prime \prime} \mathrm{N}, 02^{\circ} 38^{\prime} 43^{\prime \prime} \mathrm{E}\right.$, western Mediterranean; Fig. 1) from a $1 \mathrm{~h}$ haul at 63 to $110 \mathrm{~m}$ depth. The specimen was identified following Cohen et al. (1990) and deposited in the ichthyological collection of the Societat Balear d'Història Natural (reference number MNIB/0185).

The fish total length (TL) was measured to the nearest millimeter. The stomach contents were sorted and classified at species level. The total weight and somatic weight (total weight minus gonad and stomach content weight) were taken to the nearest gram, and the liver and gonad weight were taken with a preci- 


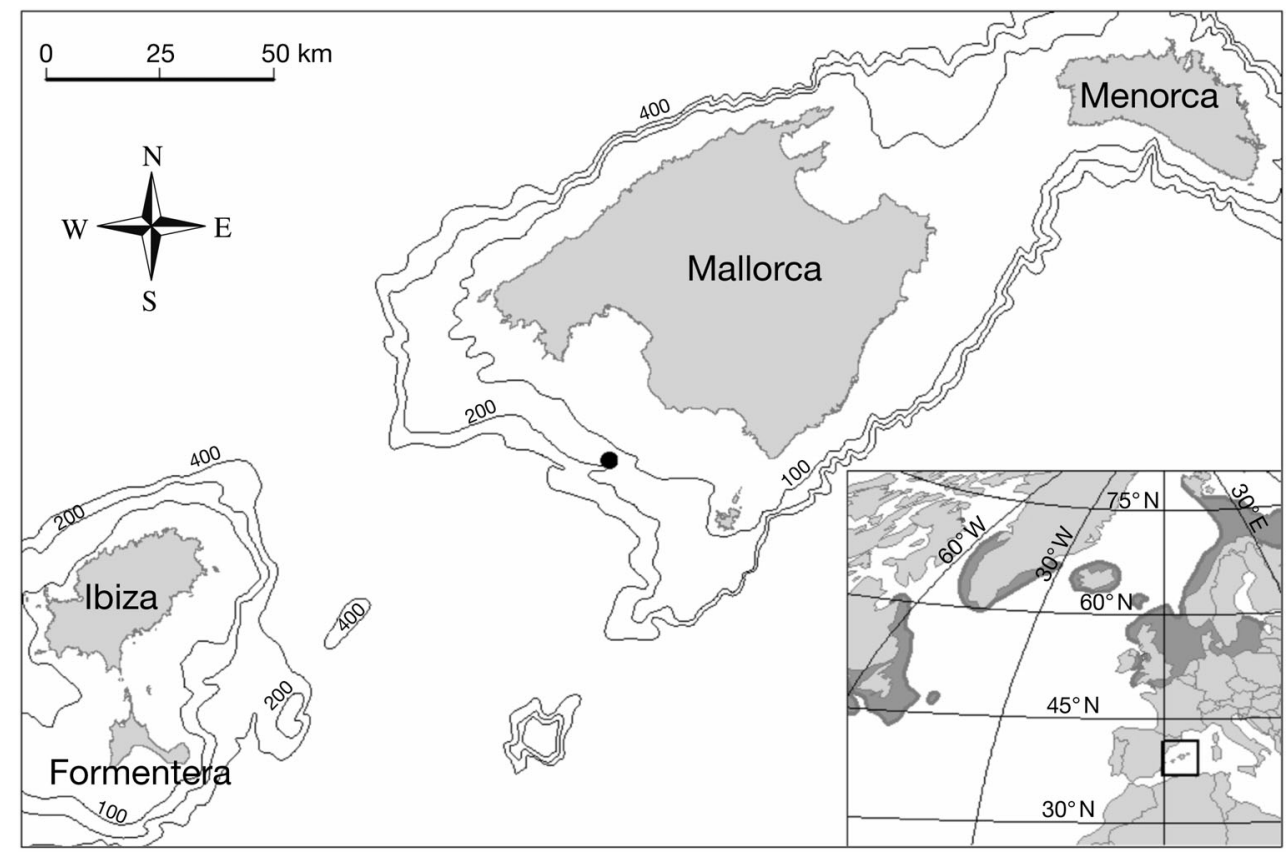

Fig. 1. Location ( ) of the cod capture off Mallorca. Inset map shows the distribution range (dark grey) of cod off European coasts (adapted from Drinkwater 2005)

sion of $0.1 \mathrm{~g}$. Fulton's $K$ and hepatosomatic index (HSI) were calculated as they are good indicators of the condition of cod (Lambert \& Dutil 1997). The gonadosomatic index (GSI) was used to describe the maturity of fish, and a portion of the central part of the right lobe of the ovary was fixed for routine microscopic examination (Luna 1968).

\section{Otolith analysis}

The sagittal otoliths were extracted, cleaned and stored dry before laser ablation inductively coupled mass spectrometry (LA-ICPMS) analysis, following methodology described by Morales-Nin et al. (2012). Ablation spots of $64 \mu \mathrm{m}$ diameter were located at $80 \mu \mathrm{m}$ intervals along a transect from the otolith core to the ventral-distal edge. Twelve isotopes were measured: ${ }^{7} \mathrm{Li}_{1}{ }^{23} \mathrm{Na},{ }^{25} \mathrm{Mg},{ }^{44} \mathrm{Ca},{ }^{55} \mathrm{Mn},{ }^{63} \mathrm{Cu},{ }^{66} \mathrm{Zn}$, ${ }^{85} \mathrm{Rb},{ }^{88} \mathrm{Sr}_{,}{ }^{114} \mathrm{Cd},{ }^{138} \mathrm{Ba}$, and ${ }^{208} \mathrm{~Pb}$, together with pelleted fish otolith (FEBS-1, Sturgeon et al. 2005; and NIES No. 22, Yoshinaga et al. 2000) and glass (NIST 610 and 612) reference materials for calibration and drift correction. Data processing detail followed Morales-Nin et al. (2012).

Digital photographs of the sections were taken after the LA-ICPMS analysis, and the position of each spot was measured in terms of distance from the core and location within a seasonal and annual growth zone, which were determined following the otolith age estimation protocols of Høie et al. (2009). Variations in the measured otolith element concentrations were plotted as time series in relation to distance from the otolith core and actual time based on spot location within the growth zones.

Potential source populations for this individual were explored from multivariate otolith element signals of cod from different NE Atlantic populations (Celtic Sea, Irish Sea, and southern North Sea/Eastern English Channel) following Geffen et al. (2011).

\section{RESULTS}

\section{Fish characteristics}

The specimen was a female $87.1 \mathrm{~cm}$ TL and $5406 \mathrm{~g}$ total weight. The stomach contents, weighing $589.5 \mathrm{~g}$, were composed of 14 knobby swimming crabs Liocarcinus tuberculatus, 3 squids (Alloteuthis subulata, Loligo vulgaris, and Illex coindetii), 3 Mediterranean horse mackerel Trachurus mediterraneus, and $10 \mathrm{Eu}-$ ropean hake Merluccius merluccius. The prey were likely consumed inside the net during the trawl, based on the digestion state and the fact that those species were also part of the capture. No other remains were found in the stomach. Once the stomach contents were extracted, the cod weighed $4816.5 \mathrm{~g}$. 
The specimen appeared emaciated, as reflected by the low condition factor $(K=0.68)$ and HSI $(0.90)$. The gonads weighed $333.6 \mathrm{~g}$, and the GSI was 7.44. The ovaries occupied $>75 \%$ of the abdominal cavity. They were granular, fibrous, well vascularized and orange-yellow. Their section was elliptic and presented a rough appearance, with visible opaque oocytes. Histological observation of the ovaries revealed a generalized atresia of vitellogenic oocytes and the abundance of stroma in ovigerous folds. Blood vessels were dilated. There were few previtellogenic oocytes in the ovarian lamellae, without any sign of degeneration. Inside the lamellae, a generalized granulomatous reaction involving groups of atretic vitellogenic oocytes could be seen. Neither postovulatory follicles nor healthy vitellogenic oocytes could be observed. Therefore, the cod was not preparing for spawning but reabsorbing the vitellogenic oocytes due to a failure in reproduction.

\section{Otolith characteristics}

The shape of the sagittal otoliths conformed to the typical characteristics for cod. The growth increments showed wide translucent increments (Fig. 2), which generally reflect life in relatively warm waters. This individual was in its fourth year of life.

$\mathrm{Na}, \mathrm{Mg}, \mathrm{Sr}$, and Ba concentrations varied across the otolith from core to edge, with peaks associated with the transition between opaque and translucent zones (Fig. 3). The first Sr peak, together with the drop in $\mathrm{Na}$ and $\mathrm{Mg}$, preceded the first translucent zone and may correspond to a translucent structure often considered to indicate a settlement mark (Morales-Nin 2000). This peak may indicate a larger shift in habitat because normally Sr concentrations are low throughout the first annual increment in cod (Limburg et al.

Fig. 3. Transect of LA-ICPMS analysis spots across cod otolith from core to edge, traversing annual growth increments (age 1-4 yr). Profiles represent concentrations of $\mathrm{Na}$ (solid grey line) and $\mathrm{Sr}$ (solid black line) on the left axis, with Mg (dashed grey line) and Ba (dashed black line) on the right axis. Dashed vertical lines represent the transition between opaque (o) and translucent zones; solid vertical lines mark the end of the translucent $(\mathrm{t})$ zone and the start of the next opaque zone and annual increment
2011). The translucent zones were marked by generally higher $\mathrm{Sr}$, as observed in previous studies (Tomas 2000, Limburg et al. 2011). The very wide first translucent zone, corresponding with an

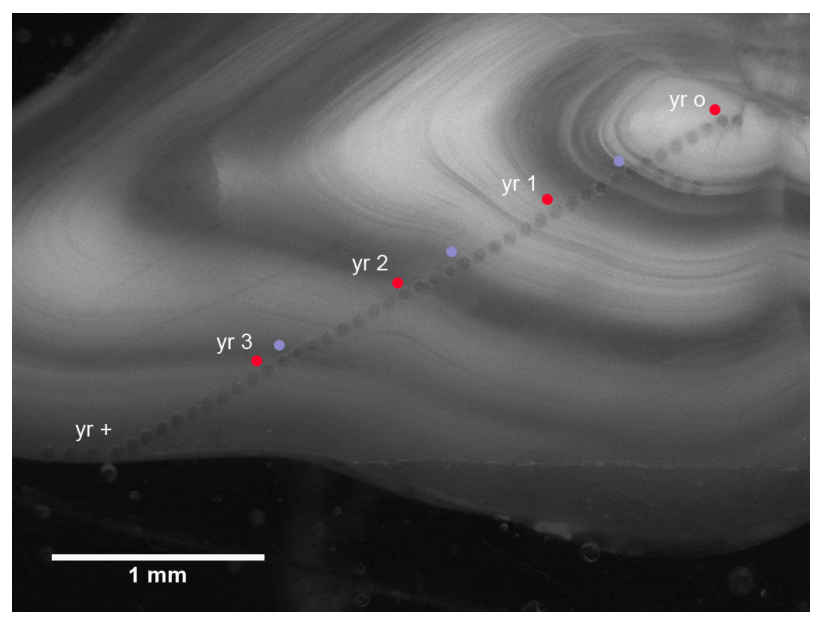

Fig. 2. Transverse section of cod otolith, showing annual growth increments and laser ablation spots from analyzed transect. Blue dots indicate start of each translucent growth increment. Red spots indicate annual growth increments. Laser spot size $=64 \mu \mathrm{m}$; distance between consecutive laserspot centers $=80 \mu \mathrm{m}$. yr + : incomplete annual growth increment

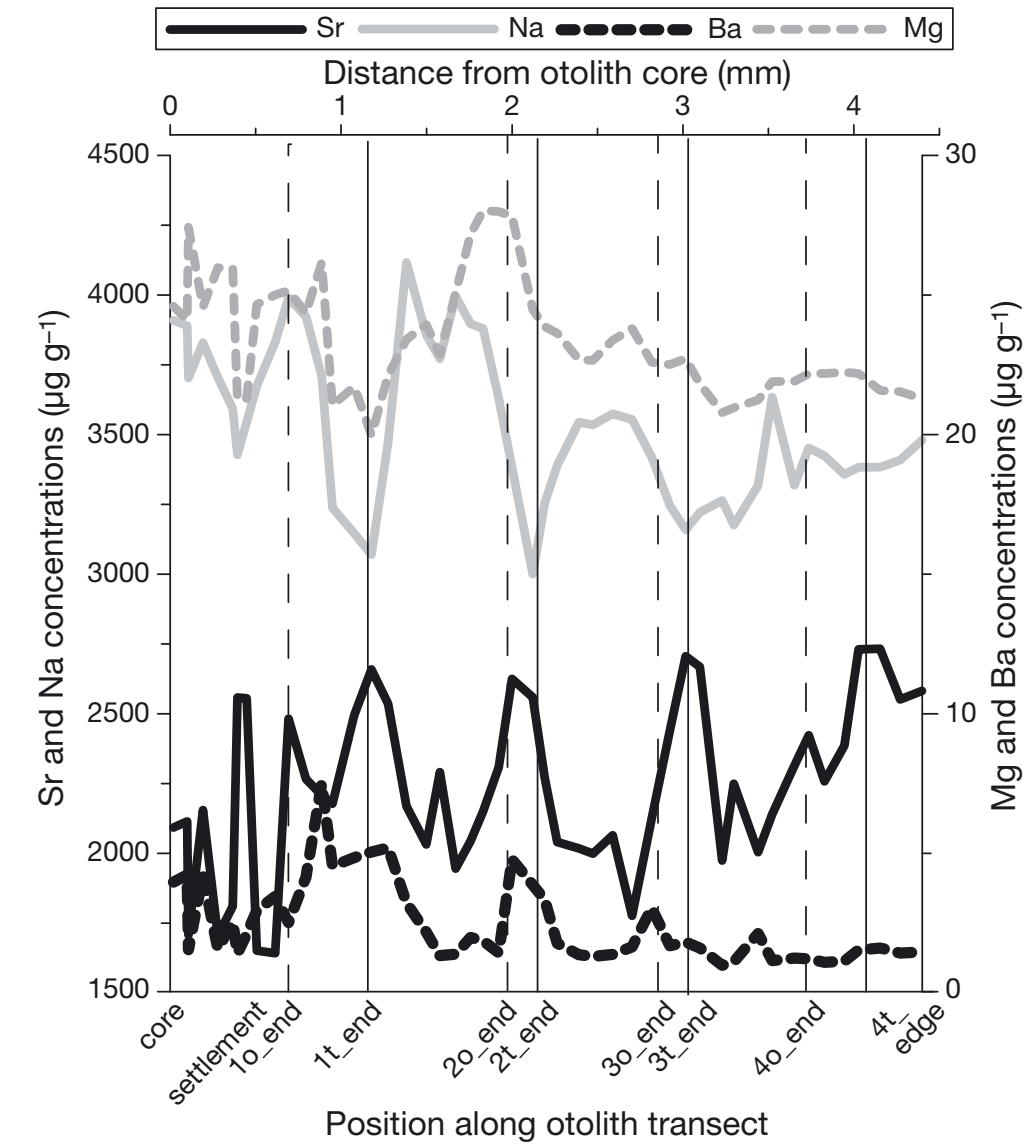


extended period of higher Sr concentrations, may represent warmer and saltier water and suggest an early migration to the Mediterranean.

From the log-transformed element concentrations in its otolith core, the Mediterranean cod was best assigned to the Eastern English Channel population but with a posterior classification probability of only 0.38 . The core concentrations of $\mathrm{Na}, \mathrm{Mn}$, and $\mathrm{Sr}$ were distinct, and these elements often indicate higher salinity waters.

\section{DISCUSSION}

Temperature is a crucial factor in determining the distribution of cod (Mieszkowska et al. 2009). Adult cod can occur in temperatures ranging from -1 to $20^{\circ} \mathrm{C}$ (Mieszkowska et al. 2009). Sea surface temperatures off the Balearic Islands range from 13 to $15^{\circ} \mathrm{C}$ during winter to $>25^{\circ} \mathrm{C}$ during summer. However, below the $50 \mathrm{~m}$ depth thermocline, the water temperature is constant at 13 to $15^{\circ} \mathrm{C}$, within the range for the species. Ocean warming is predicted to lead to a northward shift in the distribution of cod, especially at the southern limits of its distribution (Mieszkowska et al. 2009). However, this cod travelled south and was separated by ca. $2000 \mathrm{~km}$ from NW Spain waters, where it is considered sporadic (Bañon et al. 2010) and represents its southernmost occurrences along European coasts.

The fish was unlikely to be an aquarium escapee because enquiries in western Mediterranean institutions, as well as in Lisbon Aquarium, produced negative results. As far as we could assess, no one maintained cod individuals that could account for the introduction of our specimen.

Therefore, we suggest that this individual entered the Mediterranean at the end of its first year of life. It could not be reliably assigned to a specific source because the population baseline did not include all candidate sources, for example, the Bay of Biscay or occasional groups further south.

Acknowledgements. We thank A. Font and V. Botella for reporting the capture. L. Yuste prepared Fig. 1. M.Y.C. is supported by CalMarO, a Marie Curie Initial Training Network funded by the European Community's Seventh Framework Programme. J. Kosler and the Center for Element and Isotope Analysis, University of Bergen, are thanked for access to analytical equipment and facilities. We are indebted to K. Stergiou and 4 anonymous reviewers for their constructive and useful comments that greatly improved our manuscript.

\section{LITERATURE CITED}

Bañon R, Villegas-Ríos D, Serrano A, Mucientes G, Arronte JC (2010) Marine fishes from Galicia (NW Spain): an updated checklist. Zootaxa 2667:1-27

Cohen DM, Inada T, Iwamoto T, Scialabba N (1990) FAO species catalogue, Vol 10. Gadiform fishes of the world (Order Gadiformes). An annotated and illustrated catalogue of cods, hakes, grenadiers and other gadiform fishes known to date. FAO Fisheries synopsis, No. 125, Vol 10. FAO, Rome

> Drinkwater KF (2005) The response of Atlantic cod (Gadus morhua) to future climate change. ICES J Mar Sci 62: 1327-1337

> Geffen AJ, Nash RDM, Dickey-Collas M (2011) Characterisation of herring populations to the west of the British Isles: an investigation of mixing between populations based on otolith microchemistry. ICES J Mar Sci 68: 1447-1458

Høie H, Millner RS, McCully S, Nedreaas KH, Pilling GM, Skadal J (2009) Latitudinal differences in the timing of otolith growth: a comparison between the Barents Sea and southern North Sea. Fish Res 96:319-322

Jørgensen C, Dunlop ES, Opdal AF, Fiksen $\varnothing$ (2008) The evolution of spawning migrations: state dependence and fishing-induced changes. Ecology 89:3436-3448

> Lambert Y, Dutil JD (1997) Can simple condition indices be used to monitor and quantify seasonal changes in the energy reserves of Atlantic cod (Gadus morhua)? Can J Fish Aquat Sci 54(Suppl 1):104-112

Limburg KE, Olson C, Walther Y, Dale D, Slomp CP, Høie H (2011) Tracking Baltic hypoxia and cod migration over millennia with natural tags. Proc Natl Acad Sci USA 108: E177-E182

Luna LG (1968) Manual of histologic staining methods of the Armed Forces Institute of Pathology. McGraw-Hill, New York, NY

Massutí E, Valls M, Ordines F (2010) Changes in the western Mediterranean ichthyofauna: signs of tropicalization and meridianization. In: Golani D, Appelbaum-Golani B (eds) Fish invasions of the Mediterranean Sea: change and renewal. Pensoft Publishers, Sofia-Moscow, p 293-312

Mieszkowska N, Genner MJ, Hawkins SJ, Sims DW (2009) Effects of climate change and commercial fishing on Atlantic cod Gadus morhua. Adv Mar Biol 56:213-273

Morales-Nin B (2000) Review of the growth regulation processes of otolith daily increment formation. Fish Res 46 : 53-67

Morales-Nin B, Geffen AJ, Pérez-Mayol S, Palmer M, González-Quirós R, Grau A (2012) Seasonal and ontogenetic migrations of meagre (Argyrosomus regius) determined by otolith geochemical signatures. Fish Res 127: 154-165

Sturgeon RE, Willie SN, Yang L, Greenberg R and others (2005) Certification of a fish otolith reference material in support of quality assurance for trace element analysis. J Anal At Spectrom 20:1067-1071

Tomas J (2000) The relationship between otolith growth, structure and composition in temperate marine fish species. PhD thesis, University of Liverpool

> Yoshinaga J, Nakama A, Morita M, Edmonds JS (2000) Fish otolith reference material for quality assurance of chemical analyses. Mar Chem 69:91-97

Submitted: October 11, 2011; Accepted: July 11, 2012

Proofs received from author(s): October 11, 2012 